\title{
Comparative study on the physicochemical properties of k-carrageenan extracted from Kappaphycus alvarezii (doty) doty ex Silva in Tawau, Sabah, Malaysia and commercial к-carrageenans
}

\begin{abstract}
2-Carrageenan is a linear, sulphated polysaccharide that is widely used in the food industry as a gelling agent due to its lack of toxicity and biocompatibility. In this study, the physicochemical properties of $ə$-carrageenan (TA150) derived from Kappaphycus alvarezii (formerly Eucheuma cottonii) in Tawau, Sabah were investigated and compared to commercial ə-carrageenan (SeaKem CM611, Gelcarin GP812, Gelcarin GP911 NF, and Grindsted ${ }^{\circledR}$ carrageenan CL220). TA150 exhibited the lowest lightness but highest yellowness, with $\mathrm{L} *$ and $\mathrm{b} *$ values reported as 82.69 and 17.16 , respectively. The rupture strength of $\partial$-carrageenan increased significantly with increasing concentration $(\mathrm{p}<0.05)$. The water losses from $ə$-carrageenan gel increased with increasing storage times. TA150 lost the most water within 10 days of storage time. The water-holding capacity (WHC) of $\curvearrowright$ carrageenan gel was reported to be excellent $(>90 \%)$ under all storage temperatures $\left(25^{\circ} \mathrm{C}, 4\right.$ ${ }^{\circ} \mathrm{C}$ and $\overline{\mathrm{i}} 18{ }^{\circ} \mathrm{C}$ ). The moisture content, ash, acid-insoluble matter, and sulphate levels of $\curvearrowright$ carrageenan samples were reported as $3.65 \mathrm{I} 11.41 \%, 17.75 \mathrm{i} 33.18 \%, 0.22 \mathrm{i} 3.74 \%$, and $12.00 \ddot{\mathrm{I}}$ $19.71 \%$, respectively. These samples were low in fat, protein, and crude fibre contents. The potassium content in $\partial$-carrageenan was highest in Gelcarin GP812 (100.42 g/kg), followed by Grindsted® carrageenan CL220 (61.92 g/kg), TA150 (54.60 g/kg), Gelcarin GP911 NF $(40.90 \mathrm{~g} / \mathrm{kg})$ and SeaKem CM611 (15.76 g/kg). No heavy metals were detected in TA150 and the other commercial ə-carrageenan samples except for lead. However, the concentration of lead detected in the $ə$-carrageenan samples fell within the acceptable ranges $(<5 \mathrm{mg} / \mathrm{kg})$ set by the Joint FAO/WHO Expert Committee on Food Additives (JECFA).
\end{abstract}

Keyword: Eucheuma cottonii; ə-Carrageenan; Physicochemical properties; Water-holding capacity; Ash; Minerals 